\title{
Revisiting Korea's Northern Limit Line and Proposed Special Zone for Peace and Cooperation
}

\author{
Yong Seok Chang
}

\begin{abstract}
This article examines the prospects for the realization of the agreement signed at the 2007 inter-Korean summit to transform the conflict-susceptible Northern Limit Line (NLL) in the West Sea into a border area where South and North Korea jointly promote peace and prosperity. To realize this agreement the two Koreas must integrate new ideas and plans by viewing the NLL as a space of common benefit rather than a line of military confrontation. The establishment of the West Sea Special Zone for Peace and Cooperation focuses on security and economic issues. Implementation of the agreement requires particular attention to development of a comprehensive plan, including promotion of ecological, environmental, historical, and cultural assets, as well as inter-Korean fishery cooperation.
\end{abstract}

Keywords West Sea, Northern Limit Line (NLL), border area, peace settlement, common prosperity, regional cooperation

\section{Introduction}

The Northern Limit Line (NLL) in the West Sea (also called the Yellow Sea) and its surrounding areas has been a symbol of the precarious peace on the Korean Peninsula since the Korean War ended in 1953. Recurrent skirmishes between the naval forces of the two Koreas over the NLL have escalated tensions on the entire Korean Peninsula. The peace and stability of Northeast Asia would come under threat if the United States, an ally of South Korea (officially the Republic of Korea), were to become actively involved in this dispute. China objected strongly when a U.S. aircraft carrier entered the West Sea to project deterrence against North Korea (officially the Democratic People's Republic of Korea) after the South Korean warship Cheonan was sunk in the contiguous waters in 2010. This case serves as a representative example of how inter-Korean military conflict in the waters near the NLL may pose a threat to Northeast Asian peace and stability. 
This article addresses the question of how the two Koreas could break away from the consuming confrontations over the NLL and then bring sustainable peace to the waters near the line. In doing so, it delves into whether the NLL is a border or not-a question that defines the characteristics of the NLL. The article then examines ways in which the establishment of the Special Zone for Peace and Cooperation in the West Sea, agreed to by South and North Korean leaders in 2007, can be realized as a collaborative plan for achieving a sustainable peace and promoting shared use of the diverse assets found there.

This article highlights the following points: At the moment the NLL waters and the adjacent areas are "alienated borderlands" that hardly allow cross-border interactions due to strict military control and political-military tensions. However, there is potential that they could evolve into "coexistent borderlands." Furthermore, the waters near the NLL and the surrounding areas may ultimately develop into "integrated borderlands" free of any hindrance to interaction and cooperation (Martinez 1994, 1-5) and so serve as a pivotal economic zone and core pillar of the Pan-Yellow Sea Economic Bloc where peace and prosperity prevail.

\section{The Characteristics of the NLL}

The NLL is a line of military control established by an internal decision of the United Nations Command (UNC) on August 30, 1953. The Korean Sea Defense Zone, that had been proclaimed by the UNC on September 27, 1952, was abolished on August 27, 1953, as the Armistice Agreement that banned naval blockades took effect. The UNC instead established the NLL in order to

Figure 1. Northern Limit Line (West Sea)

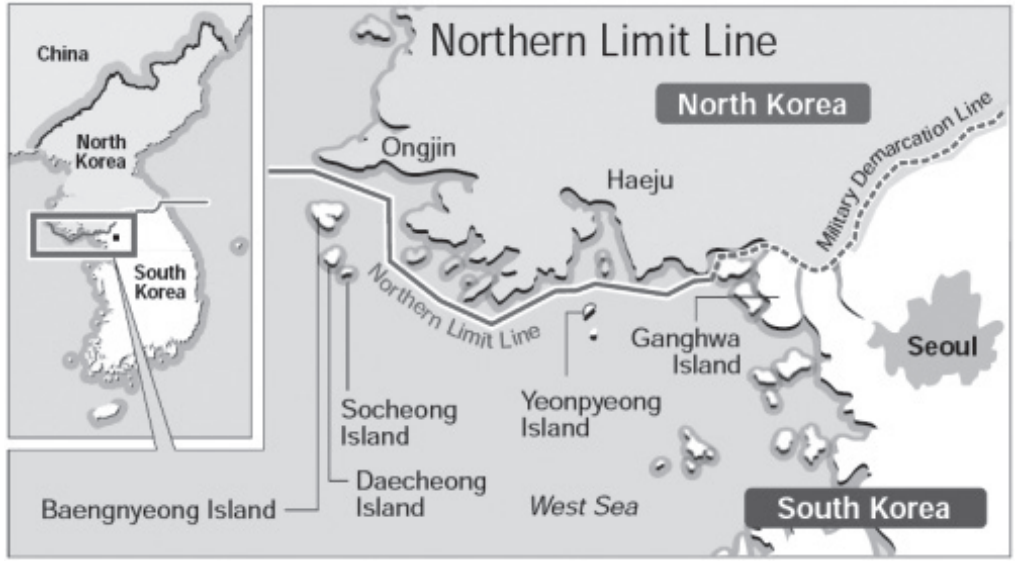

Source: Pritchard 2011. 
limit patrolling activities by naval and air units operating under UN command. Considering that the North Korean navy was practically annihilated at the time, the UNC designated the NLL primarily to effectively maintain the truce by restricting northward movement by UN-controlled vessels and aircraft so as to prevent military collisions and incursions (Suh 1999, 52; Office of Policy Planning, Policy Management and Public Relations 2007, 7).

It is important to note that establishment of the NLL was kept secret. The NLL's designation was stipulated in the United Nations Command Armistice Rules of Engagement and was issued to the Korean and U.S. navies as a secret order (C. Kim 2000, 3; S. C. Lee 2011, 94-96). This indicates that North Korea might not have been officially notified of the details of the line's designation. The Ministry of National Defense of the Republic of Korea considered, based on North Korean behavior, that "North Korea was informed of the NLL directly and indirectly" (Office of Policy Planning, Policy Management and Public Relations 2007, 18). This, however, also means that the North was not "officially" notified.

This indicates that the NLL was a line of unilateral military control and classified as a secret by the UNC in order to maintain the armistice in a stable manner by preventing armed clashes between the two Koreas. Indeed, the United Nations and the Communist side attempted but failed to reach an agreement on a maritime military demarcation line in the process of concluding the Armistice Agreement. This fact suggests that the NLL cannot act as the military demarcation line in the sea and is not directly related to the Armistice Agreement. The NLL may be considered a follow-up measure to supplement the Agreement (Jhe 2005, 118). Representatives of South Korea and the United States have also acknowledged this point in the past. ${ }^{1}$

Nonetheless, it is undeniable that the NLL has served as the de facto border preventing military conflict between the two sides (Chung 2009, 119). In particular, when the UNC at the 168th meeting of the Military Armistice Commission, held in May 1963, raised objections to the crossing and incursion of the NLL by a North Korean spy boat, North Korea showed its recognition of, and willingness to protect, the NLL by arguing that the spy boat had never crossed the line. In 1984 North Korea transferred aid supplies for South Korean flood victims along the NLL. North Korea has apparently accepted the NLL's function as the de facto border by specifying the area that had been administered by the North and the South as a nonaggression zone in the South-North Agreements on Reconciliation, Non aggression and Exchanges and Cooperation (Inter-Korean Basic Agreement) of $1992 .{ }^{2}$ Also, North Korea did not raise any objections when, in May 1993, the International Civil Aviation Organization announced a draft plan based on the NLL for coordinating the Flight Information Region of Korea, which went into effect in January 1998 (Office of Policy Planning, Policy Management and Public Relations 2007, 28-30). ${ }^{3}$

However, the fact that the NLL has functioned as the de facto border and 
contributed to maintaining the armistice does not provide any legal status to the NLL as a maritime border because the two Koreas have never agreed on or proclaimed a "maritime border" in the West Sea in a written document since the Korean War truce. South Korea in particular has not specified any regulations regarding the NLL in the Territorial Sea and Contiguous Zone Act (enacted on April 4, 2011) or in the Enforcement Decree of the same (March 23, 2013).

There has been no additional agreement concerning the border in the West Sea since the signing of the Armistice Agreement in 1953. None of the 30 agreements that were made between the UN and North Korean forces subsequent to the Armistice Agreement referred to the NLL (Chung 2011, 119). The Annex Agreement on the Implementation of and Compliance with the Basic Inter-Korean Agreement also stipulates that the existing jurisdiction should be designated as a nonaggression zone in the sea and that the maritime nonaggression "border" between South and North Korea should continue to be discussed. Thus, the potential dispute between the two Koreas over the issue of jurisdiction in the waters surrounding the five islands in the West Sea continues to surface and has yet to be addressed (Choi and Kim 2004, 114).

North Korea has regularly breached the NLL militarily since the end of the War: the attack on two South Korean Air Force aircraft in November 1956; the hijacking of fishing boats in May 1957 and April 1958; the assault on a food cargo ship in July and on a patrol boat in August 1960; the attack on navy warships in March 1961 and December 1962; the abduction of fishing vessels in March 1964, October 1965, and June 1968; the hijacking of a navy broadcast vessel in June and a fishing boat in July 1970; the attack on a fishing boat in January 1971; and the hijacking of, and assault on, a fishing vessel in February 1972 (Suh 1999, 53). The First Yeonpyeong Battle in June 1999, the Second Yeonpyeong Battle in June 2002, and the Daecheong Battle in November 2009 are other examples. More recently, the South Korean government announced that, in a major military provocation, the South Korean corvette Cheonan was sunk in March 2010 by a torpedo fired from a small North Korean submarine (Ministry of National Defense 2010).

Meanwhile, in December 1973 North Korea officially denied the existence of the NLL at the 346th regular session of the Military Armistice Commission in December 1973. And, on September 2, 1999, North Korea unilaterally declared the West Sea Maritime Border claiming that the West Sea NLL was void (KCNA 1999). On March 23, 2000, the North released the navigation order for the five islands in the West Sea (KCNA 2000). Furthermore, North Korea "officially proclaimed on January 30, 2009 to completely and finally discard" the clauses regarding the military border of the West Sea in the Inter-Korean Basic Agreement and its Annex Agreement (KCNA 2009). Finally, on March 8, 2013, North Korea explicitly declared its withdrawal from the Armistice Agreement and claimed that a state of war now existed on the Korean Peninsula - this in the year that marked the 60th anniversary of the Agreement (KCNA 2013a; 2013b). 
This situation has two implications. First, it is hardly plausible that the NLL is a viable border based on the international law concept of historical consolidation. This is so because it is not clear that the North did acquiesce to the line. It is also difficult to establish a claim that the NLL is an effective border based upon common law due to the implied agreement made between the UN and North Korean forces, because it is questionable whether North Korea's attitude toward the NLL contains unchangeable and standardized "common practice" and "legal assurance," which are requirements for common law. Common law cannot be established for a party that has persistently raised objections; thus it is doubtful whether the NLL is able to meet the requirements for common law (Jhe 2005, 126).

Second, the waters near the NLL are clearly in dispute (Chung 2011,270). One cannot say that the waters around the NLL are demarcated. This is so because the NLL cannot serve as a maritime border agreed to by the two Koreas and recognized by the international community. More importantly, one cannot say that the NLL waters are not disputed in view of the fact that North Korea, a direct stakeholder in this issue, has declared an annulment of the line and continues to enhance its military capacities reflecting an actual nullification. Against this backdrop the only choice is between a political solution and reliance on military capability in order to maintain the current status of the NLL, which is only a temporary measure under the armistice system (Jhe 2005, 113). Maintenance of the status quo through military power will become the only option should a political process be unable to produce meaningful outcomes (Choi and Kim 2004, 118). In that case, the NLL and the surrounding waters will fail to prevent disputes and remain a source of instability on the Korean Peninsula and in Northeast Asia.

The South and the North have to demonstrate their potential competence for establishing peace in the waters surrounding the NLL. Only then will it be possible to transform the NLL and the adjacent areas from a dispute-prone area into the borderlands of coexistence, interdependence, and integration. To do so, the two Koreas should take one step back from their confrontational attitudes toward the NLL itself and instead focus on other values of the NLL to promote cooperation.

This approach does not undermine the security value of the NLL. The NLL has contributed to maintaining the truce in a stable manner by supplementing the Armistice Agreement. South and North Korea must not only explore the NLL's positive function as a buffer zone that prevents inter-Korean military clashes, but also realize arms control in the Western coastal area and proactively take advantage of the region's diverse assets for the sake of shared peace and prosperity on the Korean Peninsula. By doing so, South and North Korea can actively advance the effort to address the issue of delimitation, the biggest potential obstacle in building a peace system on the Peninsula (Chang 2010a, 141-142). A 
clue to the answer lies in the West Sea Special Zone for Peace and Cooperation established by the Declaration on the Advancement of South-North Korean Relations, Peace and Prosperity (October 4 Declaration) agreed to by South and North Korean leaders in 2007.

\section{Expansion of the Concept for the Special Zone for Peace and Cooperation $^{4}$}

At the second inter-Korean summit in 2007 the leaders of South and North Korea agreed to create the Special Zone for Peace and Cooperation in the West Sea, encompassing the Haeju ${ }^{5}$ region and its adjoining waters. The two leaders also decided to designate a joint fishing zone and a peace maritime zone, to build a special economic zone, to open the Haeju port in the North and provide civilian vessels with direct passage to it, and to proactively promote joint utilization of the Han River estuary. The agreement between the two leaders on a plan for peace and mutual economic prosperity in the Western coastal border area were aimed at easing military tensions and bringing peace on the basis of economic coprosperity. The idea of the Special Zone for Peace and Cooperation focused attention on potential mutual benefits rather than focusing on the NLL as a border in interKorean confrontations. The intention was to make the NLL an area of integration, interaction, and exchange instead of a line of division that separates the inside and the outside, and the self and the other (Comelli, Greco, and Tocci 2006, 3).

The nature of the inter-Korean agreements, however, has hindered the proper utilization of the significant assets of the coastal border region in the West Sea. First, the agreements do not contain any provisions for preserving and using the ecological environment. Instead, the focus is on development plans, including the joint use of the Han River estuary and the establishment of a special economic zone. Second, no plans exist for how to preserve and use the historical and cultural assets of the region. The coastal border region in the West Sea is related to the history of the ancient Korean kingdom of Goryeo; it was part of the metropolitan area in the Goryeo period. In this regard, the concept of the Special Zone for Peace and Cooperation should be supplemented and developed in a way that enables it to preserve and utilize the diverse valuable assets and resources of the border area while maintaining the spirit of the agreement intended by the two Korean leaders.

\section{The Scope of the Western Coastal Border Region}

The Western coastal border region refers to a broad area encompassing South Korea's Ganghwa County (Gyodong and U Islands) and Ongjin County (Yeonpyeong, Daecheong, Socheong, and Baengnyeong Islands) in Incheon Metropolitan City, and North Korea’s Haeju City, Yeonan, Baecheon, Ongjin, 
Table 1. Three Zones in the Western Coastal Border Area by Environmental and Geographical Characteristics

\begin{tabular}{|c|c|c|c|}
\hline & Zone 1 & Zone 2 & Zone 3 \\
\hline Location & $\begin{array}{l}\text { Yeseong River, Imjin } \\
\text { River, and the Han } \\
\text { River estuary }\end{array}$ & Haeju Bay & $\begin{array}{l}\text { Daedong Bay and } \\
\text { Ryongyeon Peninsula }\end{array}$ \\
\hline $\begin{array}{l}\text { Area within } \\
\text { North Korea }\end{array}$ & $\begin{array}{l}\text { Gaeseong (Gaepung), } \\
\text { Yeonan, and Baecheon }\end{array}$ & $\begin{array}{l}\text { Haeju, Ongjin, } \\
\text { Gangnyeong, Byeokseong, } \\
\text { and Cheongdan }\end{array}$ & $\begin{array}{l}\text { Ryongyeon (Monggeumpo), } \\
\text { Taetan, and Jangyeon }\end{array}$ \\
\hline $\begin{array}{l}\text { Area within } \\
\text { South Korea }\end{array}$ & Ganghwa (Gyodong) & Ongjin (Yeonpyeong) & $\begin{array}{l}\text { Ongjin (Baengnyeong, } \\
\text { Daecheong, and Socheong) }\end{array}$ \\
\hline
\end{tabular}

Note: Place names in parentheses denote towns within cities or counties.

Source: Korea Peace Forum 2011.

Gangnyeong, Byeokseong, Cheongdan, Ryongyeon, Taetan, and Jangyeon Counties in South Hwanghae Province, and Gaeseong City in North Hwanghae Province.

This region is home to over 7.3 million people when the populations of Incheon Metropolitan City in South Korea and of South/North Hwanghae Provinces in North Korea are combined. Within this region, there are more than 1.9 million residents around the adjoining cities and counties alone. ${ }^{6}$ In terms of geographical characteristics and administrative jurisdiction, the Western coastal border region can be divided into three zones as shown in Table 1. Before the division of the Korean Peninsula these three areas represented distinct and important ecogeographical zones. In administrative terms Zone 1 is formed by North Korean Gaeseong City, and Yeonan and Baecheon Counties facing South Korea's Ganghwa County (Gyodong-myeon) in Incheon Metropolitan City; and in geographical terms it covers the estuary of the Han River, the Yeseong River, and the Imjin River. This zone encompasses the Kaesong Industrial Complex (KIC) along with the Han River estuary. If Incheon Metropolitan City and the KIC are connected together, and then linked to the proposed Haeju Special Economic Zone specified in the October 4 Declaration of 2007, a platform for economic growth that embraces manufacturing, logistics, and finance will be created. Zone 2 is composed of North Korea’s Haeju City, and Ongjin, Gangnyeong, Byeokseong and Cheongdan Counties facing South Korea’s Yeonpyeong-myeon, Ongjin County in Incheon Metropolitan City. This zone has rich fishery resources including the Yeonpyeong fishing ground. Thus, Zone 2 is prioritized in the inter-Korean joint fishery project, and has the potential to become the center of a peaceful maritime zone once a direct route to Haeju is opened. With regard to this zone North Korea has announced its plan for establishing "Gangnyeong International Green Pilot District" by an ordinance of the Standing Committee of the Supreme People's Assembly (KCNA 
2014). Zone 3 is of greater value in terms of eco-environmental resources, including the habitat of spotted seals around Baengnyeong Island. This zone, therefore, may become the core of the plan for a marine ecology peace park centering on ecological and environmental resources.

\section{Preservation and Utilization of the Ecology, History, and Culture}

\section{Ecological Environment}

Above all the Western coastal border area is of important value in terms of the ecological environment. The ecology of coastal regions appears to have the highest level of productivity for commodities required for human life (Wilson et al. 2005, 12-18). A coastal region is superior to land from the perspective of ecoenvironmental and economic assets; an assessment shows that a coastal region's value per unit area is five times higher than that of land areas (Costanza et al. 1997, 255-257). The West Sea coast is no exception.

The coastal border region in the West Sea includes the Han River estuary, which is the largest open water estuary in the Korean Peninsula waters. In general, an estuary serves as a link between marine and land ecologies and as a home to diverse animals and plants. The region is particularly valuable as it is where a variety of fish spend their larval stages (Lee, Kang, and Nam 2001, 2829 ), and it is estimated to have productivity per unit area 10 times higher than that of tropical rain forests (Costanza et al. 1997, 256). The region has a broad mud flat that accounts for $26 \%$ of the entire tidal flat bordering the Korean Peninsula. Towards the mouth of the Han River, the estuarine tidal flat is well developed, centering on Ganghwa, Gyodong and other islands, along with inland marshes. North Korea has a large basin mudflat connecting Daedong, Haeju, and Gangnyeong bays.

Sixty-nine preservation zones are located within the area bordered by the Han River estuary and Baengnyeong Island, and diverse protected animals, such as spotted seals, are known to inhabit the area. In addition, the area surrounding Baengnyeong and Daecheong Islands has coastal sand dunes that are well worth

Table 2. Proportion of South/North Korean Mudflat in the Western Coastal Border Region

\begin{tabular}{c|c|c|c|c}
\hline \hline \multicolumn{2}{l|}{} & $\begin{array}{c}\text { Area } \\
\left(\mathrm{km}^{2}\right)\end{array}$ & $\begin{array}{c}\text { Proportion of total in the } \\
\text { entire Korean Peninsula }\end{array}$ & $\begin{array}{c}\text { Proportion of total in North } \\
\text { and South Korea, respectively }\end{array}$ \\
\hline \multirow{2}{*}{$\begin{array}{c}\text { Western coastal } \\
\text { border region }\end{array}$} & North & 958 & $17.3 \%$ & $31.9 \%$ \\
\cline { 2 - 5 } & South & 487 & $8.7 \%$ & $19.0 \%$ \\
\hline \multicolumn{2}{c}{ Subtotal } & 1,445 & $26.0 \%$ & \\
\hline
\end{tabular}

Note: The total area of mudflat in the Korean Peninsula is estimated to be $5,550 \mathrm{~km}^{2}\left(3,000 \mathrm{~km}^{2}\right.$ in the North and 2,550 $\mathrm{km}^{2}$ in the South).

Source: Nam et al. 2007 . 
Table 3. Bird Species in the Western Coastal Border Region

\begin{tabular}{|c|c|c|}
\hline & & Bird Distribution \\
\hline \multirow[t]{3}{*}{$\begin{array}{l}\text { South } \\
\text { Korea }\end{array}$} & $\begin{array}{c}\text { The Han River } \\
\text { Estuary }\end{array}$ & $\begin{array}{l}\text { Level } 1 \text { endangered species: black-faced spoonbill, white-tailed sea } \\
\text { eagle, hawk, and golden eagle ( } 4 \text { species) } \\
\text { Level } 2 \text { endangered species: white-naped crane, swan goose, bean } \\
\text { goose, osprey, black kite, Eurasian buzzard, eagle, hen harrier, long- } \\
\text { billed ring plover, hooded crane, imperial eagle, upland buzzard, } \\
\text { rough-legged buzzard, Eurasian hobby, goshawk, and Eastern curlew } \\
\text { (16 species) } \\
\text { Protected Natural Treasures: white-naped crane (No. 250), swan goose } \\
\text { (No. 325) }\end{array}$ \\
\hline & $\begin{array}{l}\text { Baengnyeong } \\
\text { Island }\end{array}$ & $\begin{array}{l}\text { Rapacious birds and long bills } \\
\text { Protected Natural Treasures: white stork (No. 199), duck hawk (No. } \\
\text { 243) }\end{array}$ \\
\hline & $\begin{array}{l}\text { Ganghwa } \\
\text { Island }\end{array}$ & $\begin{array}{l}\text { Rare birds, including Chinese egret, Kentish plover, Mongolian plover, } \\
\text { grey plover, red-necked stint, dunlin, great knot, black-tailed godwit, } \\
\text { bar-tailed godwit, and Eurasian curlew }\end{array}$ \\
\hline $\begin{array}{l}\text { North } \\
\text { Korea }\end{array}$ & & $\begin{array}{l}\text { Approximately } 200 \text { black-faced spoonbills and } 146 \text { Siberian cranes } \\
\text { Partial habitat of grey heron, Siberian crane, and white heron } \\
\text { protected as Natural Treasures }\end{array}$ \\
\hline
\end{tabular}

Source: Nam et al. 2007.

Table 4. Preservation Zones in the Western Coastal Border Region

\begin{tabular}{l|c|l|c}
\hline \hline \multicolumn{1}{c|}{ South Korea } & \multicolumn{2}{c}{ North Korea } \\
\hline Wildlife Protection Zone & $\begin{array}{c}\text { Number of } \\
\text { designations }\end{array}$ & \multicolumn{1}{c}{ Name } & $\begin{array}{c}\text { Number of } \\
\text { designations }\end{array}$ \\
\hline Wetland Reserve & 2 & Flora Reserve & 1 \\
\hline Natural Treasures & 12 & Wetland Reserve & 3 \\
\hline Specific Islands & 9 & Natural Treasures & 37 \\
\hline Subtotal & 25 & Surine Resources Reserve & 3 \\
\hline \multicolumn{2}{|c|}{ Total (South and North Korea): 69 } & 44 \\
\hline
\end{tabular}

Source: Nam et al. 2007.

preserving as they form an ecological transition belt between sea and land.

For the protection of this vital and fragile area a number of steps are urgently required prior to further development. First, a joint ecological study of the Western coastal border region by the two Koreas is necessary in order for the region to be exploited without its valuable ecological assets being damaged. Second, based on this study, a zoning system should be introduced to divide the region by purpose; 
for instance, "preservation," "transition," and "utilization" zones in consideration of the environmental, historical, cultural, and socio-economic characteristics. Third, any proposed new projects should undergo careful and close examination on the feasibility of the project sites, such as strategic environmental assessments and preliminary environmental impact studies. Fourth, zones should be set broadly because the ecology can be effectively protected only if the zones are designated by the unit of ecology or water system. Finally, the two Koreas should cooperate with international organizations such as the United Nations Educational, Scientific and Cultural Organization. Through this cooperative approach the South and the North may designate the area of higher value for eco-environmental preservation within the entire coastal border region as a Trans-Frontier Biosphere Reserve where ecological preservation, sustainable use, and maintenance support can be promoted. Also, both Koreas should collaborate with the International Union for Conservation of Nature and Natural Resources to declare the area as a coastal/marine preservation zone and build this zone into a marine ecology peace park (Kang and Nam 2003, 30-43). ${ }^{7}$

In this context, regarding the joint use of the Han River estuary agreed upon at the inter-Korean summit in 2007, sand mining should be conducted only after a strict evaluation of not only its economic benefit but also of its potential negative impact on the environment. Dredging for shipping and tourist vessels should be done in a careful and limited manner based upon an assessment of the impact on the ecology and environment of the Han River estuary.

\section{History and Culture}

The Western coastal border region has significant value from a historical perspective as well. The region was a key trading point for the Korean Peninsula in exchanges with China from the Three Kingdoms period (1st century BC-7th century AD) and also the gateway of Goryeo (10th-14th centuries) to the world. The area from the Han River estuary to the coast of South Hwanghae Province and Baengnyeong Island was known as the center of the Korean Peninsula and Northeast Asia.

Goryeo, from its inception, traded not only with the Song dynasty but also with Southeast Asian and Arabian countries. Gaegyeong, the capital of Goryeo, grew into a global city visited by people from around the world (Kang 2004, 151-161). Goryeo interacted with the world through Byeongnan Island at the mouth of the Yeseong River, while Haeju, which belonged to Seohae Province, was situated at the outskirts of this region. Haeju became the Headquarters of the Right Commander-in-Chief in the 14th year of King Seongjong (995) and defended the capital Gaegyeong as part of the wider metropolitan area, along with the Headquarters of the Left Commander-in-Chief based in Yangju. Haeju was promoted to the status of a civil unit (Daedoho-bu) in the 17th year of King Yejong (1122) due to its importance as a strategic point for dominating the West 
Sea, which was a trade route with overseas countries including the Song dynasty. Naval forces stationed in Yeomju and Baekju were responsible for defending the capital Gaegyeong in cooperation with the naval forces based in Jeongju in Gyeonggi Province (C. Kim 2008, 172-181).

While Haeju was a strategic coastal point for controlling the West Sea and defending the capital, Ganghwa Island (now part of Incheon Metropolitan City in South Korea) served as the official capital of Goryeo for 39 years during the resistance against the Mongolian invasions in the 13th century. The island was a natural fortress surrounded by the Jo River in the north, the Gapgot River (Yeom River) in the east, and the West Sea in the west and south, as well as commanding an advantageous position for marine transportation (Kim 2004; Yoon 2010). Gyodong Island, which formed part of the capital Gaegyeong's maritime defense line, along with Ganghwa Island, was the gateway to Byeongnan Island, the international port of Goryeo. It was entered by a variety of vessels such as freighters loaded with grain paid as tax.

Diverse relics and remains from the Goryeo period are found in the Western coastal border region. In order for these historical and cultural treasures to be preserved and utilized a number of steps should be taken. First, the region's reputation and role in the Goryeo period need to be properly established. The history of this region from the prehistoric age to the Three Kingdoms, Goryeo, Joseon, Japanese colonial rule, and the Korean War periods require a comprehensive reassessment as well. Second, South-North academic exchanges, including joint research on the relics widely distributed in southern and northern parts of the coastal border region, should be promoted. Third, the two Koreas should develop joint measures to protect and manage the relics based on these joint studies. In particular, the measures for preserving the relics should be established before actual development of the region begins. Finally, South and North Korea should make use of the cultural heritage as a tourism resource and as a forum for historical and cultural education. To achieve this goal, sea cruises sailing from the Han River estuary and tourism by land connecting from Ganghwa-Gyodong to the coast of South Hwanghae Province should be considered.

\section{Coprosperity and Cooperation for Development on the Korean Peninsula}

The diverse ideas for peace and prosperity should also include actively developing and utilizing the economic resources of the coastal border area in the West Sea based on preservation and protection of historical and cultural assets as well as the ecological value of the region. Going beyond the inter-Korean agreement of 2007, the two Koreas should consider establishment of a joint fishery program, development of a Haeju special economic zone, utilization of the Haeju port, and linked development of Incheon, Gaeseong, and Haeju as a plan for comprehensive development embracing the entire coastal border region. 
Inter-Korean Fishery Cooperation

Fishery cooperation between the South and the North will maximize the economic benefits for their fishermen residing in the coastal border area by enabling expanded fishing activities in the waters. Such activity has been severely restricted because of the military confrontation between North and South. Fishery cooperation will also facilitate modernizing the North Korean fishing industry. Such cooperation can be divided into a joint fishing program and cooperation for development of the fishing industry.

The joint fishing program was included in the 20 pilot projects proposed to North Korea by the South's Chun Doo Hwan Administration in February 1982. The Working-Level Meeting on Inter-Korean Fishery Cooperation in July 2005 reached an agreement on the designation and activation of a joint fishing zone and on the restriction of illegal access by fishing crafts of third states. However, none of these commitments were implemented. South and North Korean leaders agreed again on these plans in October 2007, but to date they have not been implemented. The most critical reason that these ideas could not be implemented, regardless of the level at which the agreements were made, was that the two sides failed to designate a joint fishing area. South Korea wanted to maintain the NLL as the border while North Korea proposed placing priority on establishing a maritime military border in the West Sea. Such disagreement was repeated at the Defense Ministers Meeting and the Ministerial Meeting held after the interKorean summit in 2007 (Lee 2011, 196-273).

Both Koreas have to change their own paradigms in order to overcome this hurdle. The purpose of a joint fishing project between the South and the North is not to delimit a border, nor to officially fix the existing jurisdictions. Rather, it is to maintain the security function of the NLL while simultaneously promoting joint use and management of marine resources and maximizing economic benefits for both North and South, thus contributing to peace on the Korean Peninsula. South and North Korea therefore must confirm that the joint fishing area is unrelated to the maritime military border, in order to separate the negotiations on the joint fishing zone from the issue of delimitation in the West Sea (Sung 2009, 2). ${ }^{8}$ The two Koreas' fishery authorities, not military, should be active in designating a specific fishing zone in a way that maximizes economic benefits based upon joint research on marine resources (Chang 2010b, 32).

The feasibility of the joint fishing program may be enhanced if carried out in phases. That is, trial joint fishing activities should first start in a maritime zone that is most conducive to cooperation. Outcomes of the trials will lay the groundwork for gradually expanding the program. Neither South Korea nor North Korea proactively claims sovereignty over Maryeokri Island, which is used as a refuge and is also an area of Chinese illegal fishing. The two Koreas may designate the waters adjacent to this island as a joint fishing zone and initiate pilot projects capable of creating economic benefits by banning illegal fishing by 
Chinese vessels (Nam et al. 2006, 202-204; 2007, 90).

South and North Korea may also actively consider establishing a joint venture for implementing the joint fishing program. If the two Koreas establish a semi-governmental joint venture under the jurisdiction of South and North Korean authorities for managing all the issues related to the joint fishing zone, including regulations, supervision, and profit distribution, the joint fishing project's economic benefits will be maximized and its stability enhanced.

Cooperation on fishery development can be pursued on the basis of the confidence accumulated through the joint program. It could also be possible to build confidence by starting with cooperation on marine products processing and distribution and on fish farming in the coastal areas of South Hwanghae Province Both cooperative actions will assist in easing military tensions in the region and creating an atmosphere for peace and coprosperity. Potential longer term projects for inter-Korean cooperation on fishery development include establishment of a joint fish farming complex in the contiguous waters, domestic sales or export of the farming products, and transfer of technologies (Korea Peace Forum 2011, 149-156). Diverse projects can be pursued simultaneously or in a phased manner.

Linked Development of Incheon, Gaeseong, and Haeju

While the aim of fishery cooperation is to promote coprosperity centering on the border region in the West Sea, the purpose of the linked development of Incheon, Gaeseong, and Haeju is to form a core pillar of the Pan-Yellow Sea Economic Bloc by connecting the key growth hubs in the region. This concept may utilize Haeju port and Haeju special economic zone agreed in the 2007 inter-Korean summit.

The most important aspect of the proposed economic integration in the coastal border area is the Incheon Free Economic Zone (IFEZ), the aim of which is to establish an advanced international city connected with Incheon International Airport. The IFEZ is composed of Yeongjong District, the proposed hub of Northeast Asian air logistics through the airport; the Songdo District proposed to serve as a hub city of international trade connected with the airport, seaport, and teleport, and as a city where industry, education, and research are integrated; and the Cheongna District designed as a hub of finance and other global business affairs, and as a location for tourism and relaxation (ibid., 164-165). The diverse roles of the IFEZ may be connected with the industrial development of Gaeseong and Haeju.

Gaeseong is not only significant for its historical and cultural characteristics as the capital of Goryeo, but it is the city where the Kaesong Industrial Complex (KIC) is located. The industrial complex, a symbol of mutual prosperity, combines South Korean capital with North Korean labor. Since it first began operation with a pilot project in December 2004, the KIC has continued to grow despite the ups and downs in inter-Korean relations. As of March-April 2014, some 125 businesses were in operation and 52,000 North Koreans were working at the 
industrial complex. The accumulated output from January 2005 to late March 2014 reached 2.3 billion dollars. ${ }^{9}$ The IFEZ's functions of international logistics, finance, and R\&D will play critical roles once the KIC is further expanded and developed. That is, a synergy will be created when the KIC and the IFEZ are combined.

Before the division of Korea Haeju, located in North Korea's South Hwanghae Province, was an important transportation hub connecting Seoul, Pyongyang, and China. And today commerce and industry are well developed in this region. Currently, the Hwanghae-Cheongnyeon railroad line connects with the Gyeongui line at Sariwon, and the Baecheon line runs toward Gaeseong and the Ongjin Line toward Ongjin (Institute for Peace Affairs 2004a, 19, 72). Furthermore, the Haeju port serves as both a domestic and international port. Haeju port, one of the eight major ports in North Korea, primarily handles cement and minerals, and processes approximately $10 \%$ of North Korea's total trade cargo (Office of Investigation and Research 2010, 114-115). A direct route between the Haeju and Incheon ports was in operation after the Inter-Korean Shipping Agreement went into force in August 2005, but the route was closed as a part of the sanctions on the North following the sinking of the Cheonan in 2010 and has not yet reopened. Haeju is one of the four small industrial districts in North Korea, along with Gimchaek, Anju, and Wonsan. Haeju specializes in cement, smelting, and fertilizer manufacturing, and also deals with light industries, including mining machinery, building materials, textile manufacturing, food, and basic commodities (ibid., 26).

Mid- and long-term plans are required to achieve the type of regional economic integration that will maximize the synergy effect benefitting from the advantages of linking Incheon Metropolitan City with the proposed IFEZ, and with Gaeseong and Haeju. In this respect, Incheon may endeavor to become an economic hub in Northeast Asia by focusing on finance, trade, and business, and by using Incheon International Airport and the Incheon port. Gaeseong can nurture components manufacturing and light industries with a focus on small and medium-sized companies. By linking a direct route between Haeju and Incheon, Haeju could pursue construction of a free economic zone centered on the building material industry, heavy and chemical industry, component assembly, and processing of agro-fishery products. Furthermore, Incheon, Gaeseong, and Haeju could be integrated in stages into a free economic zone. To support such economic cooperation, expressways and bridges connecting Haeju, Gaeseong, and Incheon (Gyodong) should be constructed along with a direct sea route between the Haeju and Incheon ports, and then a logistics network established that links to Incheon International Airport (Korea Peace Forum 2011, 178-194).

With these steps the coastal border region in the West Sea will comprise a single logistical infrastructure centering on Incheon International Airport and 
Figure 2. Concept of the Special Zone for Peace and Cooperation, the Incheon-Gaeseong-Haeju Free Economic Zone, and Pivotal Economy on the Korean Peninsula
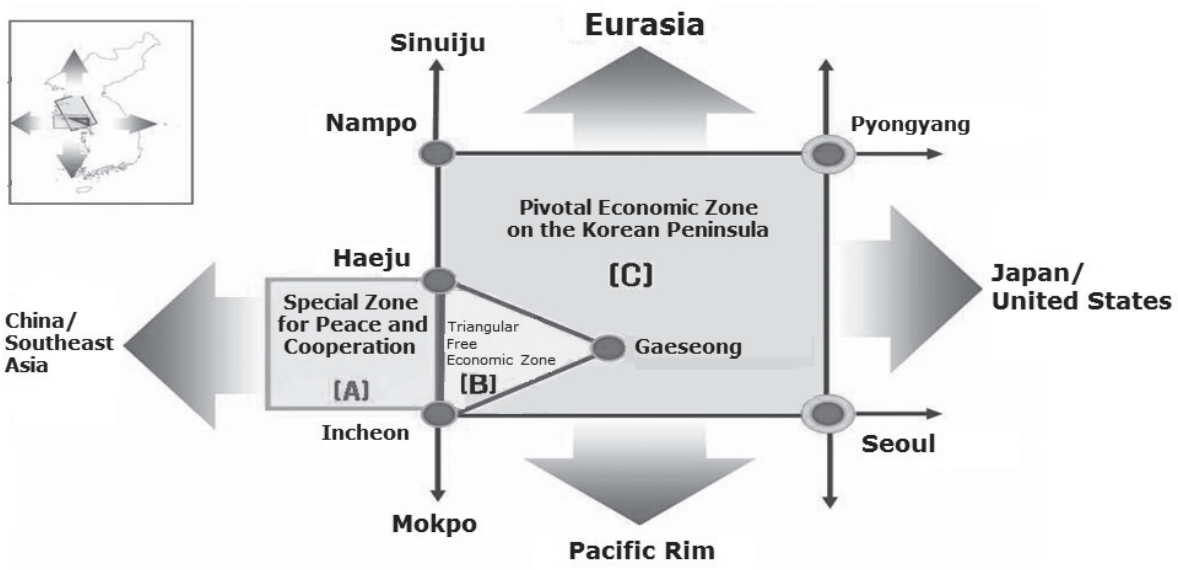

Note: Labels are translated from the Korean original.

Source: Park and Lee 2007.

the Incheon port, and represent a steppingstone for the region to grow into a globalized economic zone. If linked to the Yellow Sea Special Economic Zone in China and other regional cities, it will be possible for the border region to make a leap forward, becoming the core pillar of economic growth in Northeast Asia and a pivotal economic zone of the Korean Peninsula.

\section{Conclusion}

A paradigm shift regarding the West Sea could open a new path to the future. If the border area is viewed as a region for cooperation and integration instead of a division line, the isolated border region of confrontation and control may be transformed into a space for coexistence, interdependence, and integration. If the two Koreas continue to fix their eyes on the NLL only, military tension will never be eased. The South will continue to consolidate the NLL, whereas the North will continually try to nullify it. However, if the two Koreas turn their eyes to the ecological, environmental, historical, and cultural elements, and above all, consider those living in the coastal border region, they can overcome military confrontation. Then it will be possible to develop the Korean Peninsula and realize a new vision of cooperation for the benefit of peaceful coexistence.

Eight years have passed since the two Korean leaders agreed to construct the Special Zone for Peace and Cooperation. The Korean Peninsula is in need of a political environment that promotes practical discussions on how to settle peace in the West Sea. To do so, the agreement needs to be revisited. Those issues overlooked 
or missed in the past have to be comprehensively reviewed and developed into policy alternatives. The rediscovery of ecological, historical, and cultural resources and treasures is part of this process. Expanded ideas are also required for the two Koreas to connect and develop Incheon, Gaeseong, and Haeju into a pivotal economic zone on the Korean Peninsula, to promote cooperation in the fishing industry, and to preserve and utilize the ecological environment, history, and culture.

It is also important to rediscover the critical importance of Incheon Metropolitan City, a border maritime city, which is adjacent to the five West Sea islands bordering with South Hwanghae Province in North Korea. The role of the central government in South Korea is inevitably important due to the military and security issues involved. Nonetheless, an integrated border region can be realized should South and North Korean cities, with the leadership of Incheon, succeed in creating cooperative spaces based on the ecological environment, history, culture, and the potential for mutual prosperity, and also in restoring the communities and lifestyles naturally formed in the past.

\section{Notes}

This article is a translated and extensively revised version of Chang Yong Seok, 2013, "Seohae bukbang hangyeseon gwa pyeonghwah yeoblyeok teukbyeol jidae jaelon" [The West Sea NLL and Special Zone for Peace and Cooperation Revisited], Tongil munje yeongu 25 (1).

1. Regarding this matter, Lee Yang Ho, then Minister of National Defense of the Republic of Korea, in answering questions at the Plenary Session of the National Assembly on July 16, 1996, said: “The North Korean naval vessel's crossing of the NLL does not constitute a violation of the Armistice Agreement... [The NLL] is a line set by South Korea regardless of the Armistice Agreement. Strictly speaking, the NLL is a line unilaterally drawn by us in international waters... (Are you saying that it is okay for North Korea to cross the line?) Yes. The line is drawn by us to protect our fishing boats and to prevent our navy vessels from reaching close to the North regardless of the Armistice Agreement... So, the NLL is a line designated in international waters." (National Assembly of the Republic of Korea 1996, 65). Earlier, in 1975, U.S. Secretary of State Henry Kissinger in a cable to the United States Embassy in Seoul regarding the crossing of the NLL by an aircraft and a vessel of North Korea wrote: "The NLL does not have international legal status. The NLL was unilaterally designated, and North Korea did not accept it. Furthermore, the NLL is contrary to international law and the United States Law of the Sea, insofar it purports to unilaterally divide international waters... The United States government and the United Nations Command cannot support the statement by South Korea that such incident has occurred in South Korean territorial waters and exclusive fishing zone" (Kissinger 1975).

2. The map and the marking of the "Military Demarcation Line" on page 254 of Joseon jungang yeongam 1959, published by North Korea's KCNA in 1959, are commonly referred to as grounds for the claim that North Korea recognized and accepted the NLL. However, 
the line marked as the Military Demarcation Line on this map is insufficient as it is drawn only between the five South Korean islands in the West Sea and South Hwanghae Province of North Korea. The map has no marking in the contentious waters between Yeonpyeong Island and Socheong/Daecheong Islands. Thus, the scant lines between islands and land probably are to respect the adjacent sea surfaces of the two Koreas defined by the Armistice Agreement, rather than a Maritime Military Demarcation Line (Chung 2011, 281-282).

3. A Flight Information Region is established to facilitate search and rescue of distressed aircraft, and thus it is generally set according to the sovereign areas of the respective country. However, a Flight Information Region does not delimit a country's territory or territorial waters.

4. This section is based on a report commissioned by Incheon Metropolitan City and conducted by the Korea Peace Forum with the participation of the author (Korea Peace Forum 2011).

5. Romanization of South and North Korean place names, book titles, and other text follows the official Republic of Korea Ministry of Education system. Exceptions are established official designations such as the Kaesong (Gaeseong) Industrial Complex, Pyongyang, and names of prominent political figures.

6. To be more specific, as of 2013, the population of Incheon Metropolitan City was 2,879,782 persons, among which 66,735 and 20,698 residents respectively resided in Ganghwa County and in Ongjin County (87,433 in total) [Resident Registration Data by City, County, and District of Korean Statistical Information Service. http://kosis.kr/eng/statisticsList/ statisticsList_01List.jsp?vwcd=MT_ETITLE\&parentId=A\#SubCont (accessed August 3, 2014)]. The Incheon Free Economic Zone (IFEZ), which may become a core pillar of the proposed economic zone connecting Incheon, Gaeseong, and Haeju, was home to 194,325 people as of 2013, and this figure is expected to reach 643,000 by 2020 when the development project is completed [Introduction to the Incheon Free Economic Zone. http://www.ifez.go.kr (accessed August 3, 2014)].

North Korea's South Hwanghae Province bordering with Incheon recorded a population of 2,310,485 in 2008. The coastal area of South Hwanghae Province has a total population of 1,330,817, allocated as follows: Haeju City, 273,300; and the following counties: Yeonan $(158,845)$, Baecheon $(159,826)$, Ongjin $(152,878)$, Gangnyeong $(106,827)$, Byeokseong $(90,752)$, Cheongdan $(142,607)$, Ryongyeon $(90,102)$, Taetan $(64,258)$, and Jangyeon $(91,422)$. The population of North Hwanghae Province is 2,113,672, among which 308,440 are residents of Gaeseong City. The total North Korean population in the adjoining cities and counties is $1,639,257$. North Korea has not released data on population by region since the 2008 census (Central Bureau of Statistics 2009, 21-22).

7. Concerning the establishment of a marine peace park on the West Sea coast, see Nam et al. $(2005 ; 2006 ; 2007)$.

8. In this context, it is fair to say that the criteria for setting the NLL, such as equi-distance and equi-area, are also likely to undermine the project, as they eventually raise issues of designating a maritime border (Korea Peace Forum 2011, 144).

9. Data on the Kaesong Industrial Complex provided by the Ministry of Unification. http://eng.unikorea.go.kr/content.do?cmsid=1822 (accessed August 3, 2014). 


\section{References}

Central Bureau of Statistics. 2009. DPR Korea 2008 Population Census National Report. Pyongyang: Central Bureau of Statistics.

Chang, Yong Seok. 2010a. "Hanbando pyeonghwa cheje wa pyeonghwa hyeopjeong: Gaenyeom, jaengjeom, chujin banghyang" [The Peace System and Peace Treaty in the Korean Peninsula: Concept, Issues, and Directions]. Tongil munje yeongu 22 (1): 123152.

Chang, Yong Seok. 2010b. "Seohae Bukbang hangyeseon jiyeok pyeonghwa jeongchak noryeok gwa hyanghu jeongchaek chujin banghyang" [Efforts for Peace in the Northern Limit Line Region and Future Policy Directions]. NamBuk jeongsang hoedam 3-junyeon ginyeom haksul hoeui jaryojip [Proceedings of the Conference in Commemoration of the Third Year of the Inter-Korean Summit]. Jointly hosted by the Institute for Future Korea, Korea Peace Forum, and Incheon International Exchange Center, October 4, 2010. Seoul: Gukhoe Doseogwan.

Choi, Jong-hwa, and Kim Young-gyu. 2004. "Bukbang hangyeseon gwa Seohae 5-do jubyeon suyeok ui haeyangbeop munje" [Issues in the Law of the Sea Regarding the Waters near the Five Islands in the West Sea and the Northern Limit Line]. Susan haeyang gyoyuk yeongu 16 (1): 110-124.

Chung, Tai-uk. 2009. "Seohae Bukbang hangyeseon eun nugureul wihan seoninga?" [For Whom is the West Sea Northern Limit Line?]. Yeoksa bipyeong 88: 115-124.

Chung, Tai-uk. 2011. "Seohae Bukbang hangyeseon jaeron: Yeonpyeongdo pogyeok sageon eul gyegiro" [The West Sea Northern Limit Line Revisited: From the Attack on Yeonpyeong Island]. Minju beophak 45: 115-296.

Costanza, Robert, Ralph d'Arge, Rudolf de Groot, Stephen Farber, Monica Grasso, Bruce Hannon, Karin Limburg, Shahid Naeem, Robert V. O’Neill, Jose Paruelo, Robert G. Raskin, Paul Sutton, and Marjan van den Belt. 1997. “The Value of the World's Ecosystem Services and Natural Capital.” Nature 387: 253-260.

Comelli, Michele, Ettore Greco, and Nathalie Tocci. 2006. "Working Paper: From Boundary to Borderland: Transforming the Meaning of Borders in Europe through the European Neighbourhood Policy." http://www.eu-consent.net/library/brx061012/ Comelli-Greco-Tocci_D40.pdf (accessed August 3, 2014).

Hyundai Research Institute. 2012 "Hyeonan gwa gwaje: Kaeseong gongdan hwakdae, NamBuk modu ege piryohada!" [Current Issues and Tasks: Everyone Needs an Expansion of the Kaesong Industrial Complex!]. http://hri.co.kr/board/ReportView. asp (accessed August 3, 2014).

Institute for Peace Affairs, and North Korean Publisher of Science Encyclopedia. 2004a. Joseon hyangto daebaekgwa 8: Hwanghaenamdo [(North) Korean Encyclopedia of Geography and Culture 8: South Hwanghae Province]. Seoul: Institute for Peace Affairs.

Institute for Peace Affairs, and North Korean Publisher of Science Encyclopedia. 2004b. Joseon hyangto daebaekgwa 8: Hwanghaenamdo II [(North) Korean Encyclopedia of Geography and Culture 8: South Hwanghae Province II]. Seoul: Institute for Peace Affairs. 
Jhe, Seong-ho. 2005. "Bukbang hangyeseon (NLL) ui beopjeok yuhyoseong gwa Hanguk ui daeeung banghyang" [The Legal Effectiveness of the Northern Limit Line and Directions of Korea's Response]. Jungang beophak 7 (2): 107-150.

Kang, Bong-ryong. 2004. "Goryeo sidae ui haeyang munhwa wa guksa gyogwaseo gisul" [Marine Culture in the Goryeo Period and Descriptions in Korean History Textbooks]. Hangukssa hakbo 16: 151-161.

Kang, Dae-seok, and Nam Jung-ho. 2003. Seohae yeonan jeopgyeong jiyeok NamBukHan hyeomnyeok gwalli bangan [Measures for Inter-Korean Management and Cooperation for the Western Coastal Border Region]. Seoul: Hanguk Haeyang Susan Gaebalwon.

KCNA ([North] Korean Central News Agency). 1959. Joseon jungang yeongam 1959 [Joseon Central Almanac 1959].

KCNA. 1999. "Joseon inmingun chongchammobu teukbyeol bodo" [Special Report of the General Staff of the North Korean Army]. September 2.

KCNA. 2000. "Joseon inmingun haegun saryeongbu '5-gae seom tonghang jilseo' gongpo" [Proclamation of the "Navigational Order on the Five Islands" by the Navy Headquarters of the Korean People's Army]. March 23.

KCNA. 2009. "Jopyeongtong BukNam daegyeol sangtae haeso habui muhyohwa reul seonpo" [The CPRF's Promulgation on Nullification of the Agreement for Resolving the State of Confrontation between the South and the North]. January 30.

KCNA. 2013a. "Wurineun joguk tongil daejeon ui jeolho ui gihoe reul jeoldaero nochiji aneul geosida: Joguk pyeonghwa tongil wiwonhoe seongmyeong" [We Will Never Lose the Golden Opportunity for a Great War for Reunification of Our Motherland: Statement by the CPRF]. March 8.

KCNA. 2013b. "Jigeum isigak buteo chorae doel modeun pagukjeok hugwa ui chaegimeun jeonjeok euro Miguk gwa goeroe paedang I jige doel geosida: Joguk pyeonghwa tongil wiwonhoe daebyeonin seongmyeong" [The U.S. and the Puppet Group in the South Will be Held Accountable for All the Catastrophic Consequences from This Moment: Statement by the Spokesperson of the CPRF]. March 11.

KCNA. 2014. "Joseon eseo dodeul e gyeongje gaebal gudeul eul naeogiro gyeoljeong" [A Decision Was Made to Establish Economic Development Zones]. July 23.

Kim, Chang-hyun. 2004. "Goryeo Gaegyeong gwa Gangdo ui doseong bigyo gochal” [A Comparison between the Capital Cities of Gaegyeong and Gang-do of Goryeo]. Hanguksa yeongu 127: 143-176.

Kim, Chang-hyun. 2008. "Goryeo sidae Seohaedo jiyeok ui wisang gwa sawon" [The Reputation and Temples of Seohae-do in the Goryeo Period]. Hanguksa hakbo 16: 169203.

Kim, Young Koo. 2000. "Bukhan i jujang haneun Seohae haesang gyeonggyeseon gwa tonghang jilseo e daehan bunseok" [An Analysis on the Maritime Border and Navigation Order in the West Sea Proposed by North Korea]. Seoul Gukjebeop Yeongu 7 (1): 1-34.

Kissinger, Henry. 1975. "Summary, Public Affairs Aspects of North Korea Boat/Aircraft Incident, State 046188." February 28. http://aad.archives.gov/aad/createpdf?rid=93953\& $\mathrm{dt}=2476 \& \mathrm{dl}=1345$ (accessed April 3, 2015).

Korea Peace Forum. 2011. "Seohae pyeonghwa hyeomnyeok teukbyeol jidae guchuk silhaeng bangan yeongu: Seohae pyeonghwa beonyeong gwa Incheon inisyeotib" [A Study on the Measures for Establishing the Special Zone for Peace and Cooperation in the West Sea: 
Peace and Prosperity in the West Sea and the Incheon Initiative]. Report on a Research Project Commissioned by the Incheon Metropolitan City Government. Seoul: Korea Peace Forum.

Korean Statistical Information Service. 2014. Resident Registration Data by City, County, and District. http://kosis.kr/eng/statisticsList/statisticsList_01List.jsp?vwcd=MT_ ETITLE\&parentId=A\#SubCont (accessed August 3, 2014).

Lee, Chang-hee, Kang Dae-seok, and Nam Jung-ho. 2001. Hagu · seokho yukhae jeoni suyeok tonghap hwangyeong gwalli bangan yeongu [A Study on the Measures for Integrated Environmental Management of Estuary and Lagoon Transition Waters between Land and Sea]. Seoul: Hanguk Haeyang Susan Gaebalwon.

Lee, Sang-Chul. 2011. Bukbang hangyeseon: Giwon - Wigi · Sasu [The Northern Limit Line: Origin, Crisis, and Protection]. Seoul: Seonin.

Martinez, O. J. 1994. “The Dynamics of Border Interaction.” In Global Boundaries, ed. Clive H. Schofield. London and New York: Routledge, 1-15.

Ministry of National Defense. 2010. Hapdong josa gyeolgwa bogoseo: Cheonanham pigyeok sageon [Report of Joint Investigation: The Attack on the Warship Cheonan]. Seoul: Gukbangbu.

Ministry of National Defense. 2012 Gukbang baekseo [2012 Defense White Paper]. Seoul: Gukbangbu.

Nam, Jeong-ho, Chang Won-keun, Choi Ji-yeon, Yook Keun Hyung, Choi Hee Jung, and Lee Won Kap. 2005. "Seohae yeonan haeyang pyeonghwa gongwon jijeong mit gwalli bangan yeongu" [A Study on the Designation and Management of the West Sea Coast Marine Peace Park]. Seoul: Hanguk Haeyang Susan Gaebalwon.

Nam, Jeong-ho, Chang Won-keun, Choi Ji-yeon, Yook Keun Hyung, Choi Hee Jung, and Lee Won Kap. 2006. "Seohae yeonan haeyang pyeonghwa gongwon jijeong mit gwalli bangan yeongu (II)" [A Study on the Designation and Management of the West Sea Coast Marine Peace Park (II)]. Seoul: Hanguk Haeyang Susan Gaebalwon.

Nam, Jeong-ho, Chang Won-Keun, Choi Ji-yeon, Yook Keun Hyung, Choi Hee Jung, and Lee Won Kap. 2007. "Seohae yeonan haeyang pyeonghwa gongwon jijeong mit gwalli bangan yeongu (III)" [A Study on the Designation and Management of the West Sea Coast Marine Peace Park (III)]. Seoul: Hanguk Haeyang Susan Gaebalwon.

National Assembly of the Republic of Korea. 1996. "Je 180 hoe Gukhoe Gukhoe bonhoeui hoeuirok je 7 ho" [The Seventh Proceedings from the 180th National Assembly Plenary]. http://likms.assembly.go.kr/kms_data/record/data1/180/180za0007b. $\mathrm{PDF} \#$ page $=1$ (accessed August 3, 2014).

Office of Investigation and Research, Korea Finance Corporation. 2010. Bukhan ui saneop 2010 [North Korean Industries 2010]. Seoul: Hanguk Jeongchaek Geumyun ggongsa.

Office of Policy Planning, Policy Management and Public Relations, Ministry of National Defense. 2007. Bukbang hangyeseon e gwanhan uri ui ipjang [Our Stance on the Northern Limit Line]. Seoul: Gukbangbu.

Park, Yang-ho, and Lee Sang-jun. 2007. "Hanbando wa Dongbuk-A gongdong sijang chawon eseo ui Seohae pyeonghwa hyeomnyeok teukbyeol jidae ui bijeon gwa baljeon gusang" [The Concept of Development and Vision of the Special Zone for Peace and Cooperation in the West Sea as a Joint Market between the Korean Peninsula and Northeast Asia]. Gukto jeongchaek bripeu 159: 1-8.

Pritchard, Jack. 2011. “The Reality of the Northern Limit Line." The Korea Herald, January 5. 
http://www.koreaherald.com/view.php?ud=20110105000968 (accessed April 16, 2015).

Suh, Choo Suk. 1999. "Bukbang hangyeseon ui yeoksajeok gochal gwa hyeonsiljeok gwaje" [A Historical Review of the Northern Limit Line and Realistic Tasks]. Hyeondae inyeom yeongu 14: 47-65.

Sung, Souk-Kyung. 2009. "Seohae 5-do: Galdeung suyeok eul pyeonghwa suyeok euro" [The Five Islands in the West Sea: From the Waters of Conflicts towards Waters of Peace]. Bukhan haeyang susan libyu 3: 9-15.

Wilson, Matthew A., Robert Costanza, Roelof Boumans, and Shuang Liu. 2005. "Integrated Assessment and Valuation of Ecosystem Goods and Services Provided by Coastal Systems." In The Intertidal Ecosystem: The Value of Ireland's Shores, ed. James G. Wilson. Dublin: Royal Irish Academy, 1-24.

Yoon, Yong-hyuk. 2010. "Goryeo doseong euro seoui Gangdo ui jemunje” [Issues of Gang-do as the Capital City of Goryeo]. Hangukssa hakbo 40: 75-104.

Yong Seok Chang is Senior Researcher of the Institute for Peace and Unification Studies, Seoul National University. He served as Director of the Korean National Security Council from February 2003 to January 2006 and Presidential Assistant Secretary for Unification, Foreign and Security Policy from January 2006 to February 2008. He has worked as a member of the Policy Advisory Committee to the Ministry of Unification since 2012. He has co-authored several books, including The Rise of China and East Asia: Awareness and Strategies (Baeksanseodang, 2012), and Strategies of North Korea Transformation for Unification (KINU, 2011) (both in Korean). E-mail: cyskkj@daum.net 
